\title{
Quantitative Comparison of the Structural Features of Slow and Fast Neuromuscular Junctions in Manduca ${ }^{1}$
}

\author{
MARY B. RHEUBEN \\ Department of Anatomy, Michigan State University, East Lansing, Michigan 48824
}

\begin{abstract}
The multiterminal slow and fast neuromuscular junctions of the moth Manduca sexta were compared using scanning, thin-section, and freeze-fracture techniques to see what structural features might underlie their functional differences. Slow neuromuscular junctions, here formed on tonic muscle fibers, produce a facilitating e.j.p. the amplitude of which is $1 / 5$ to $1 / 3$ the size of a fast excitatory junction potential (EJP) and the duration of which is nearly four times longer.

A slow junction consists of a single terminal branch that is shorter in length than either of the pair of branches that a fast junction forms close together on the muscle fiber. Within the junction, slow nerve terminals exhibit longer, more frequent constrictions and are very varicose compared with fast. Since fast larval junctions on tonic muscle fibers are also varicose (Schaner and Rheuben, 1985), this is unlikely to represent an intrinsic property of the nerve. However, calculations of the length constants of the varicose versus nonvaricose shapes indicate that the effect of passive cable properties on normal functioning may act to limit the length of the slow terminals more than that of fast. Even though the varicose shape can be predicted to prolong the time course of the EJP, calculations show that, at the measured length, this would not explain the very long EJP that is observed.

Within the neuromuscular junctions, the synapses are characterized on the muscle membrane by a patch of densely packed particles on the external leaflet and on the nerve membrane by a single linear active zone. The total number of synapses per slow junction is about $1 / 3$ that of fast junctions. There is a weak correlation between average area of the individual postsynaptic particle patches and cross-sectional area of the muscle fibers that transcends nerve and muscle fiber types. The average lengths of active zones from the two types do not differ significantly. However, the number of particles per active zone in slow junctions is about $55 \%$ of the number in fast active zones. Chemically fixed slow nerve terminals have a greater density of synaptic vesicles remaining than do fast. If a proportion of the active zone particles represent structures directly involved in the probability of transmitter release, such as $\mathrm{Ca}^{++}$channels, then the
\end{abstract}

Received June 28, 1984; Revised December 10, 1984

Accepted December 11, 1984.

${ }^{1}$ The Manduca eggs were provided by the Insect Physiology Laboratory, Department of Agriculture, Beltsville, MD, thanks to Dr. James Svoboda and Mrs. Thelma Golden. Financial support was from National Institutes of Health Grant NS17132 and Research Career Development Award NS00301. The author is grateful to Ms. Pamela Schaner for her excellent technical assistance and to Drs. Ann Kammer and Margaret Titmus for critical reading of the manuscript. latter two characteristics may jointly reflect differences in capability to release and mobilize transmitter that would partly explain the different EJP amplitude and facilitation properties.

Several examples of quantitative structural differences have been described for neuromuscular junctions exhibiting different physiological properties. In arthropods, excitatory and inhibitory neuromuscular junctions can be distinguished in thin sections by the differences in sizc and shapc of their synaptic vesicles (Uchizono, 1967; Atwood et al., 1972; Nakajima and Reese, 1983), with inhibitory vesicles tending to respond to chemical fixation by flattening. In addition, the diameter of the region of close apposition between nerve terminal and muscle membranes around each active zone, usually termed the synaptic contact or plaque, is about four times longer in inhibitory terminals in the cockroach (Aizu, 1982), 1.6 to 2.3 times longer in locust (Titmus, 1981), or from 1.18 to 1.95 times greater in area in crayfish (Jahromi and Atwood, 1974; Franzini-Armstrong, 1976).

Fast and slow excitatory terminals, so named because of the duration of the excitatory junction potentials that they produce, also have been observed to differ (but not consistently) in the length of the synaptic contact, fast being about three times longer than slow (lobster: Hill and Govind, 1981) or fast being slightly shorter than slow (locust: Titmus, 1981). The size of synaptic vesicles of fast terminals is $50 \%$ larger in diameter in locust (Titmus, 1981), and the overall shape of the slow terminal is larger and more variable in diameter (lobster: Hill and Govind, 1981; locust: Titmus, 1981).

Individual motor axons may form terminals with diverse properties on different muscle fibers or in different regions of the same muscle fiber. In the distal accessory flexor muscle of the lobster, different terminals of the same axon release relatively high or low amounts of transmitter. The terminals generating the larger synaptic potentials have greater numbers of presynaptic dense bodies (lobster: Govind and Chiang, 1979; Meiss and Govind, 1980; crab: Atwood and Marin, 1983).

Freeze-fracture studies of a number of neuromuscular junctions have shown that a well-defined particle specialization occurs in the membrane of the nerve terminal adjacent to the cytoplasmic presynaptic dense bar (frog: Dreyer et al., 1973; crayfish: Franzini-Armstrong, 1976; insect: Rheuben and Reese, 1978). Since the presynaptic active zone is likely to be directly involved in transmitter release, either as a structure for holding and mobilizing synaptic vesicles or as the site for calcium entry (Pumplin et al., 1981), one might expect to see differences in its structure or length in terminals of differing function. Likewise, the postsynaptic membrane is decorated with a dense array of particles opposite the presynaptic active zones. The shape and distribution of the particle patches are characteristic of each synapse that has been described, with particles of glutamate synapses cleaving with the external leaflet and those of cholinergic junctions cleaving with the cytoplasmic leaflet (Rash and Ellisman, 1974; Franzini-Armstrong, 1976; Rheuben and Reese, 1978; Rosen- 
bluth, 1978). There is substantial evidence (see Fambrough, 1979) that these particles represent the postsynaptic receptors or receptorion channel complexes, and so shape and area of the particle patch might be expected to be correlated with function.

The present study compares two types of neuromuscular junction, slow and fast excitatory, in the insect Manduca sexta, combining freeze-fracture techniques with thin-seclion and scanning microscopy to describe quantitatively those details of their morphology that might relate specifically to synaptic function. An earlier study (Schaner and Rheuben, 1985) has shown that the same motor neuron exhibits differences in the morphology of its neuromuscular junction when it innervates a tonic muscle fiber (larval stage) than when it innervates the phasic (adult) muscle. Consequently, for parts of the present study, the possibility has been considered that features of the postsynaptic cell influence the structure of the junction which is formed jointly by nerve and muscle fiber.

\section{Materials and Methods}

The muscles compared in this study are from the adult moth Manduca sexta. Experimental animals were raised on an artificial diet (after the methods of Yamamoto, 1969), from eggs provided by the Insect Physiology Laboratory, Department of Agriculture, Beltsville, MD. The third axillary muscles and the subalar muscles are adjacent to each other and can be exposed simultaneously for recording or fixation (Rheuben, 1972). The techniques for recording the junction potentials intracellularly from the muscle fibers are conventional and have been described previously (Rheuben, 1972; Rheuben and Kammer, 1980)

For ultrastructural studies, the muscles are perfused ( $4 \%$ paraformaldehyde, $1 \%$ glutaraldehyde, and $0.2 \mathrm{mM} \mathrm{CaCl}_{2}$ in $0.1 \mathrm{M}$ phosphate buffer) in situ in a slightly stretched position. Small bundles of fibers are dissected free after $1 / 2 \mathrm{~h}$ and placed in vials of fresh fixative. Subsequent processing of tissue for thin sectioning, freeze-fracture, or scanning microscopy is as described in detail in Rheuben and Reese (1978). For freeze-fracture, the tissue is equilibrated in $23 \%$ glycerol and frozen between pairs of gold discs for fracture in a complementary replica holder at $-118^{\circ} \mathrm{C}$ in a Balzer $360 \mathrm{M}$ with electron beam guns. Tissue examined with the scanning electron microscope is not coated with gold but rather is impregnated with osmium bound with thiocarbohydrazide and then dehydrated and critical point dried. Muscles bearing a thick basal lamina such as the tonic larval and adult fibers require a preliminary treatment with collagenase and acid to make the underlying structures visible. This procedure, modified from Evan et al. (1976), is described in detail in Schaner and Rheuben (1985). For thin sectioning, tissue pieces are block stained in uranyl acetate, dehydrated, and embedded in English araldite. Replicas and sections are examined with either a Philips 201 or a JEOL $100 \mathrm{CX}$ electron microscope

For quantitative measurements, the image magnifications of the electron microscope negatives are calibrated with a replica grating. The enlarger magnifications are recorded for each batch of prints, and a final magnification is determined for each photograph.

Measurcments of junctional structures are made from the photomicro graphs using a Zenith LSI-11 and a Summagraphics bit pad. Borders of the postsynaptic plaque regions are determined either by the abrupt curvature of the muscle membrare as it turns away from the parallel contact with the nerve (freeze-fracture and thin section) or by the distribution of the postsyn-

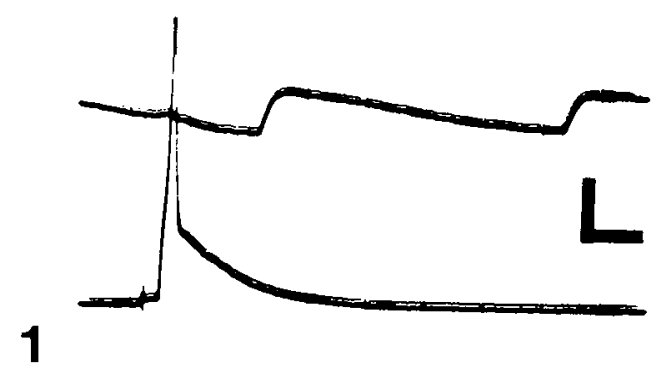

Figure 1. Simultaneous recording of synaptic responses from middle third axillary (top trace) and subalar (bottom trace) muscles. The fast EJP is topped by an active membrane response. Note the long time course of the spontaneously generated slow EJPs. Calibration bar is $10 \mathrm{mV} / 20 \mathrm{msec}$. From Rheuben and Kammer, 1983; used with permission of Alan R. I iss Inc. aptic particles (freeze-fracture) and the electron dense membrane specialization (thin section). Presynaptic plaques, which might be expected to be slightly smaller than postsynaptic plaques, were measured in freeze-fractured material only and were determined by the borders of the stiffened-appearing part of the terminal. This shape may very well be due to the way that the pre- and postsynaptic membranes are held parallel to each other at the synaptic cleft during fixation. In many fractures, part of the presynaptic plaque and part of the postsynaptic plaque are exposed so that only a combined measurement can be made. Measurements of the cross-sectional areas of muscle fibers were made directly from thick sections using an Optomax System II image analyzer.

\section{Results}

\section{Description of the muscles to be compared}

The primary muscles selected for this study, divisions of the subalar, the dorsal longitudinal, and of the third axillary muscles, are cach innervated by single motor neurones, either of the slow or fast type. The two lateral bundles of the subalar and the five bundles of the dorsal longitudinal muscle have been used extensively in previous studies (Rheuben, 1972; Rheuben and Reese, 1978; Rheuben and Kammer, 1980). Electrophysiological measurements and tension records indicate that each of the lateral bundles of the subalar is innervated by a single fast motor axon, separable by stimulus strength. The medial bundle appears to have some doubly innervated fibers and was carefully excluded. The dorsal longitudinal has also been used previously, and each bundle is innervated by a single fast axon (Rheuben and Kammer, 1980). The subalar and the dorsal longitudinal are typical phasic muscles.

The details of the ultrastructure and physiology of the third axillary muscle will be described elsewhere (M. B. Rheuben, manuscript in preparation). Briefly, it is composed of three distinct parts, here referred to as the upper, middle, and lower portions. The upper and lower portions contain typical arthropod "intermediate" type muscle fibers, which have the ratio of thick to thin filaments found in tonic muscle fibers, but which have numerous mitochondria as in phasic fibers. Each is innervated by a single fast motor axon. The middle portion of the third axillary contains tonic muscle fibers which are innervated by a single slow axon.

The electrophysiological characteristics that distinguish insect slow and fast excitatory neuromuscular junctions and make them suitable for a structure-function comparison are the peak amplitude of the excitatory junction potential (EJP), the time course of the EJP, and the likelihood that facilitation or depression will occur with paired or repeated stimuli. Fast neuromuscular junctions produce a 20 to $30 \mathrm{mV}$ EJP which is usually topped by an overshooting active membrane response. (In the membrane of insect muscle fibers, the depolarization produced by the active membrane response does not propagate along the fiber.) The duration of the EJP is 20 to 30 msec. For subthreshold EJPs, the fast axon is more likely to show depression of the amplitude of the second EJP. If coritrast, the neuromuscular junctions of the slow axon produce a small EJP, 5 to $15 \mathrm{mV}$, of markedly longer duration, 80 to $100 \mathrm{msec}$, and which in many cases show facilitation. Figure 1 shows examples of slow and fast EJPs recorded from Manduca, and other cases are reviewed by Hoyle (1975).

It should be noted that all of the muscles mentioned above are also innervated by very small axons which run in the neural lamella of the nerve twigs and which contain dense-cored vesicles (Rheuben and Kammer, 1983). By analogy with results on locusts (Evans and O'Shea, 1978; Hoyle et al., 1980; Evans and Siegler, 1982), these axons are likely to be neurosecretory, with a modulatory or hormonal effect on the physiology of the two muscles. Their morphology is unlikely to be confused in the studies presented here because they are not known to make distinct neuromuscular junctions.

\section{The neuromuscular junction}

The three-dimensional structure and membrane specializations of fast motor neurones on phasic muscle fibers, the subalar and the 

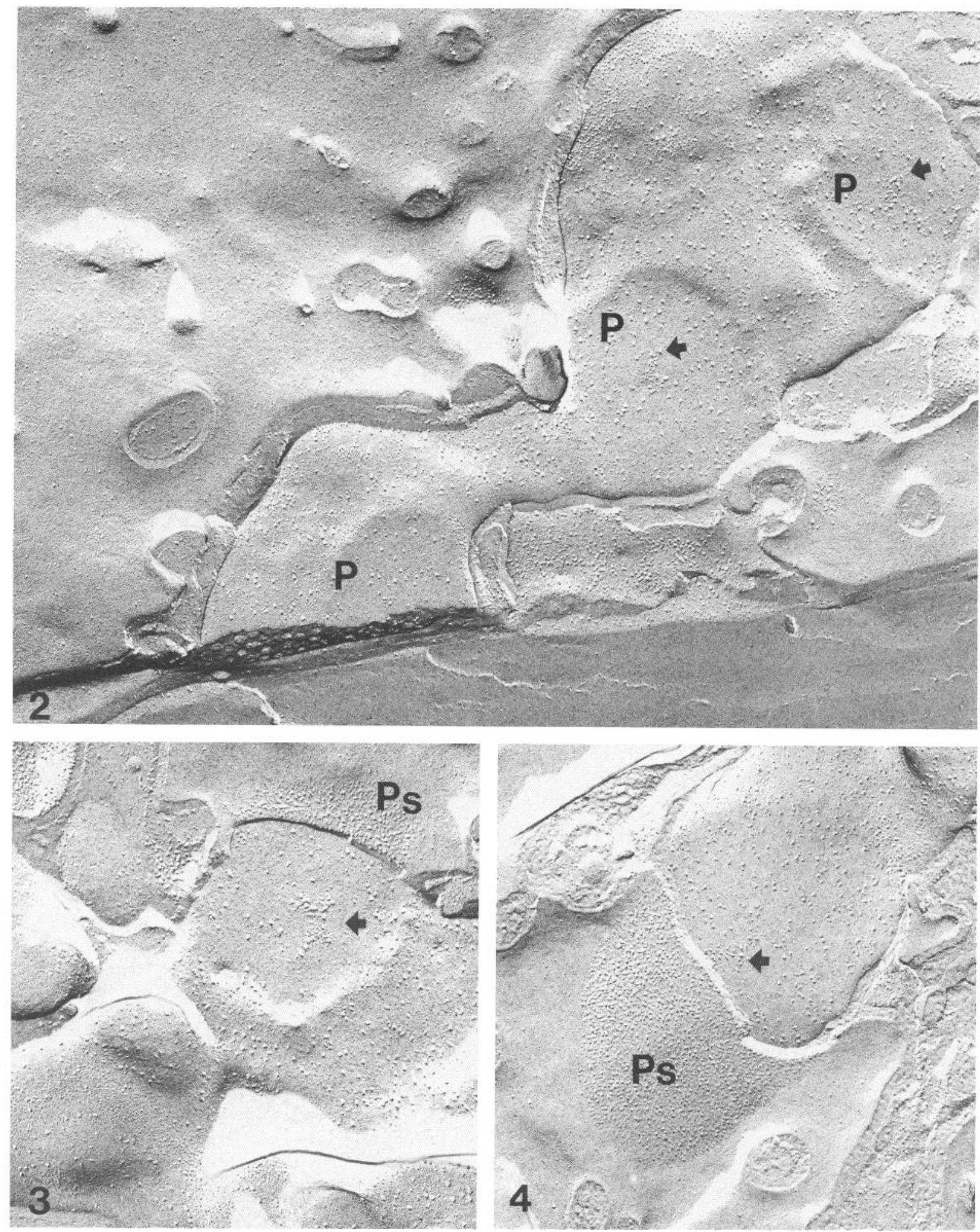

Figure 2. Portion of slow nerve terminal from middle third axillary muscle. The cytoplasmic leaflet of the nerve is shown with part or all of three plaques $(P)$. The small bands of particles that are associated with the active zones are indicated by arrows. The plaques are on wider regions of the terminal; these wide regions are separated from each other by narrower necks. The external leaflet of the muscle fiber is visible on either side of the nerve. The crossfractured circular profiles are of glial fingers that indent the sarcolemma. Magnification $\times 51,900$.

Figure 3. Cytoplasmic leaflet of a nerve plaque showing the irregular shape of the active zone (arrow) that occurs in some slow terminals. Part of the postsynaptic particle specialization is shown on the adjacent external leaflet of the muscle fiber $(P S)$. Magnification $\times 61,700$.

Figure 4. Plaque from slow terminal, cytoplasmic leaflet. Nearly half is covered by postsynaptic external leaflet (PS), showing the approximate congruence of the pre- and postsynaptic plaque areas. Part of a band of active zone particles is marked with an arrow. Magnification $\times 60,800$. 

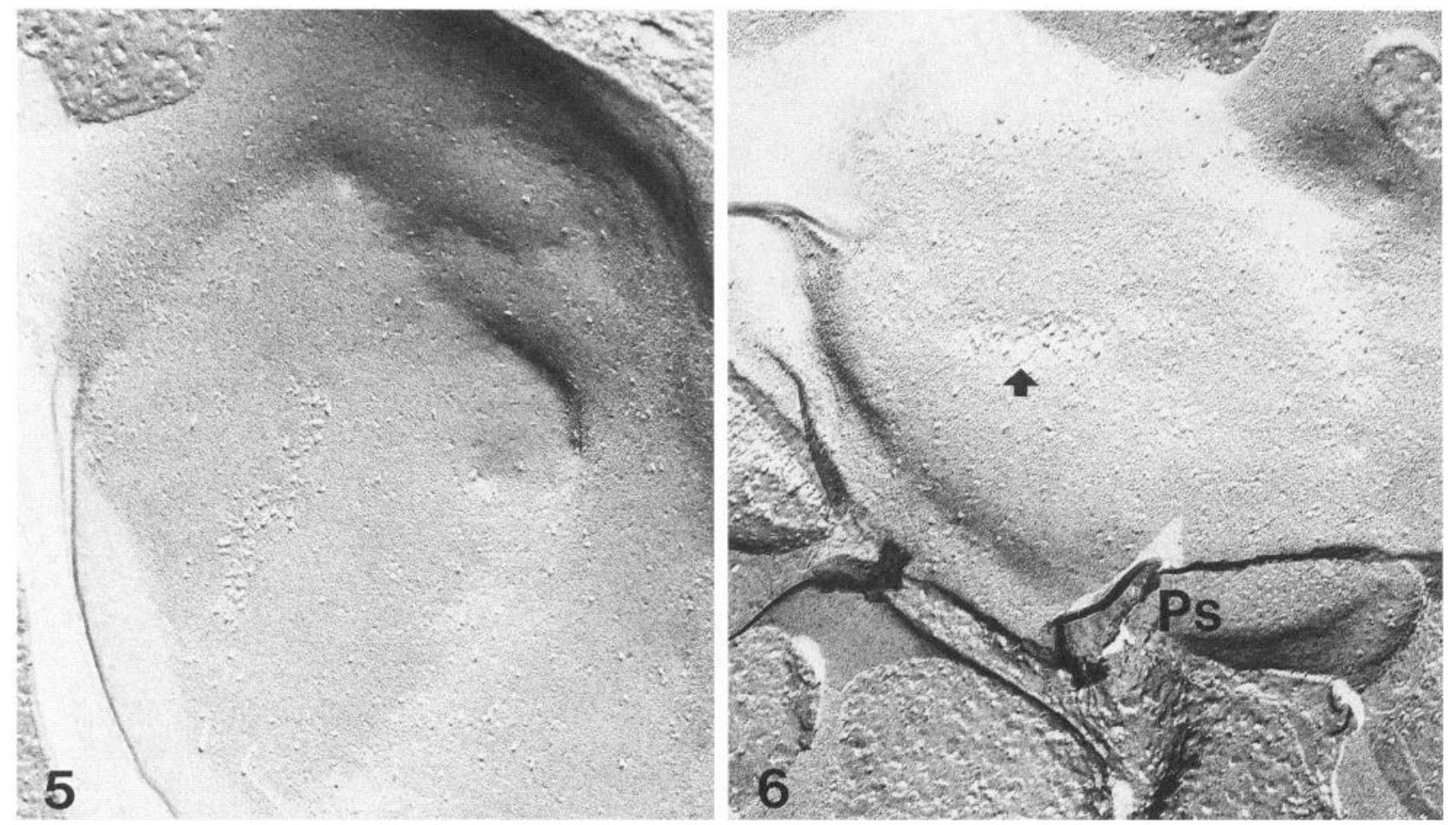

Figure 5. External leaflet of slow nerve plaque showing what may be two adjacent active zones or one long one. This kind of active zone is rare. Magnification $\times 84,200$.

Figure 6. External leaflet of slow nerve plaque with active zone (arrow) and portion of cytoplasmic leaflet from postsynaptic muscle fiber exhibiting a patch of pits in the plaque region (PS). Magnification $\times 90,300$.

dorsal longitudinal muscles, have been described previously (Rheuben and Reese, 1978; Rheuben and Kammer, 1981). In fast and slow neuromuscular junctions, the nerve terminal closely apposes the muscle at oval or round "plaques." A linear active zone occupies the center of each plaque in the nerve terminal, and densely packed large particles occupy the entire plaque area in the muscle membrane. Processes from glial cells are interposed between the plaques and intertwine with smaller processes from the muscle fiber. The membrane specializations and glial associations of slow and fast neuromuscular junctions are qualitatively similar but quantitatively different.

\section{Characteristics of the plaques and postsynaptic membrane specializations}

The slow neuromuscular junctions of the tonic middle third axillary muscle have smaller regions of contact or "plaques" than those formed by fast terminals on phasic muscles. Figures 2 through 6 show typical plaques from the middle third axillary muscle, and Table I compares the dimensions of the plaques from slow and fast terminals. Measurements were taken from freeze-fracture and thinsection views. The width, length, and sometimes, total area could be measured from fractures containing primarily the membrane of the nerve terminal (most fractures contain some of both). Similarly, measurements were taken from fractures containing entirely the postsynaptic membrane. Mean lengths and widths of either pre- or postsynaptic plaques were used to estimate areas using the formula $\pi a b / 4$, which assumes that an ellipse approximates the oval shape.

From thin sections, a mean cross-sectional length of the postsynaptic plaque was obtained by measuring the length of the electron dense subsynaptic membrane (Fig. 7). To exclude measurements through the periphery of the oval contact region, postsynaptic specializations were measured in sections containing a presynaptic active zone, since this structure usually lies in the middle of the plaque. The areas, both measured and estimated, of plaques from middle third axillary fibers are smaller than those of fast subalar terminals, ranging from 0.31 to $0.34 \mu \mathrm{m}^{2}$ for slow to 0.40 to 0.49 $\mu \mathrm{m}^{2}$ for fast (Table I). These differences are significant at the 0.01 level for the freeze-fracture data and at the 0.05 level for the sectioned material ( $t$ test).

It should be pointed out that the shapes of the postsynaptic particle specializations, while largely oval in both slow and fast junctions, occasionally include a few very small patches or a few larger, irregular patches. The large, odd-shaped patches are most often found where the bottom of the terminal comes into contact with the muscle fiber, and they appear to be several patches coalescing.

Since middle third axillary muscle fibers have smaller diameters than subalar fibers, the smaller individual plaque areas might be related to the amount of current required to produce a given depolarization in these fibers (with internal resistance being inversely proportional to cross-sectional area). To see if this size relationship continued in other muscles, the fibers and plaques of the upper and lower third axillary muscle were compared. Both of these muscles are of the "intermediate" type but differ substantially from each other in average fiber diameter; both are innervated by nerves with fast EJPs. In freeze-fractured material, junctions formed on both these muscles most closely resembled those formed by fast axons on fast muscle fibers, but some appeared more varicose than typical. Plaque lengths and widths of "upper" and "lower" were intermediate between those of "middle" third axillary and subalar muscles and were significantly different from each other (Table II).

The giant larval dorsal longitudinal muscle fibers which are tonic, but which are innervated by a fast axon that will later innervate the phasic adult muscle fibers, provide one more example for comparison. These muscle fibers have plaque areas which, on the average, are not significantly greater than those of the subalar or the adult dorsal longitudinal muscles (Schaner and Rheuben, 1985). However, some larval junctions have groups of plaques that are notably larger than any seen so far on other muscles. Twenty-four out of 97 larval plaques have lengths from 1.0 to $1.5 \mu \mathrm{m}$ as opposed to the five 
TABLE I

Estimates of areas of postsynaptic specializations formed in junctions of slow nerve with tonic muscle fibers and fast nerve with phasic muscle fibers

\begin{tabular}{|c|c|c|}
\hline & $\begin{array}{c}\text { Slow } \\
\text { (Middle Third Axillary) }\end{array}$ & Fast (Subalar) \\
\hline \multicolumn{3}{|l|}{ Nerve plaque } \\
\hline Width & $\begin{array}{c}0.57 \pm 0.12^{a} \mu \mathrm{m} \\
n=63\end{array}$ & $\begin{array}{c}0.67 \pm 0.095 \mu \mathrm{m} \\
n=16\end{array}$ \\
\hline Length & $\begin{array}{c}0.76 \pm 0.14 \mu \mathrm{m} \\
n=59\end{array}$ & $\begin{array}{c}0.81 \pm 0.13 \mu \mathrm{m} \\
n=25\end{array}$ \\
\hline Measured area & $\begin{array}{c}0.34 \pm 0.12 \mu \mathrm{m}^{2} \\
n=50\end{array}$ & $\begin{array}{c}0.46 \pm 0.14 \mu \mathrm{m}^{2} \\
n=12\end{array}$ \\
\hline \multicolumn{3}{|l|}{ Muscle plaque } \\
\hline Width & $\begin{array}{c}0.52 \pm 0.10 \mu \mathrm{m} \\
n=9\end{array}$ & $\begin{array}{c}0.63 \pm 0.13 \mu \mathrm{m} \\
n=5\end{array}$ \\
\hline Length & $\begin{array}{c}0.63 \pm 0.19 \mu \mathrm{m} \\
n=8\end{array}$ & $\begin{array}{c}0.86 \pm 0.22 \mu \mathrm{m} \\
n=10\end{array}$ \\
\hline Measured area & $\begin{array}{c}0.31 \pm 0.12 \mu \mathrm{m}^{2} \\
n=13\end{array}$ & $\begin{array}{c}0.49 \pm 0.27 \mu \mathrm{m} \\
n=4\end{array}$ \\
\hline \multicolumn{3}{|l|}{$\begin{array}{l}\text { Combined muscle and nerve } \\
\text { plaque }\end{array}$} \\
\hline Width & $\begin{array}{c}0.55 \pm 0.13 \mu \mathrm{m} \\
n=79\end{array}$ & $\begin{array}{c}0.66 \pm 0.10 \mu \mathrm{m} \\
n=21\end{array}$ \\
\hline Length & $\begin{array}{c}0.73 \pm 0.13 \mu \mathrm{m} \\
n=71\end{array}$ & $\begin{array}{c}0.83 \pm 0.16 \mu \mathrm{m} \\
n=35\end{array}$ \\
\hline Measured area $(\rho<0.01)$ & $\begin{array}{c}0.33 \pm 0.12 \mu \mathrm{m}^{2} \\
n=75\end{array}$ & $\begin{array}{c}0.47 \pm 0.17 \mu \mathrm{m}^{2} \\
n=16\end{array}$ \\
\hline $\begin{array}{l}\text { Calculated area }(\pi \mathrm{ab} / 4) \text { from } \\
\text { both pre- and postsyn- } \\
\text { aptic plaques }\end{array}$ & $0.32 \mu \mathrm{m}^{2}$ & $0.43 \mu \mathrm{m}^{2}$ \\
\hline $\begin{array}{l}\text { Length of postsynaptic spe- } \\
\text { cialization, thin section ( } p \\
\sim 0.05 \text { ) }\end{array}$ & $\begin{array}{c}0.63 \pm 0.17 \mu \mathrm{m} \\
n=48\end{array}$ & $\begin{array}{c}0.71 \pm 0.14 \mu \mathrm{m} \\
n=20\end{array}$ \\
\hline $\begin{array}{l}\text { Calculated area, from thin sec- } \\
\text { tions }\left(\pi d^{2} / 4\right)\end{array}$ & $0.31 \mu \mathrm{m}^{2}$ & $0.40 \mu \mathrm{m}^{2}$ \\
\hline
\end{tabular}

${ }^{a}$ Mean $\pm \mathrm{SD}$.

largest of 35 plaques from adult subalar muscles, which have lengths from 1.0 to $1.2 \mu \mathrm{m}$. Other larval junctions, and especially junctions which are fractured at the tip of the nerve terminal, have plaques that are closer to the average. Since the fibers of the instar examined (early fifth) will continue to grow in size, it is possible that this population consists of a mixture of junctions or plaques of various developmental ages. The available data suggest a trend relating increasing muscle fiber size to increased individual plaque area, but with an apparent upper limit. Further nerve-muscle combinations need to be examined before any conclusions can be drawn.

The density and appearance of the particles in the postsynaptic membrane specializations of the two types of terminals were examined in enlarged micrographs in order to see if there was any suggestion of an intrinsic difference in the receptors or in the numbers of receptors per patch. At the level of resolution imposed by unidirectional shadowing, there was no difference in the appearance of the individual particles. The mean number of particles per $\mu \mathrm{m}^{2}$ is $4,337 \pm 847$ (SD) $/ \mu \mathrm{m}^{2}$ ( $n=29$ samples) from middle third axillary postsynaptic plaques and $4,146 \pm 606 / \mu \mathrm{m}^{2}(n=10)$ from subalar plaques ( $4080 \pm 730 / \mu \mathrm{m}^{2} ; n=11$; from previously published data, Rheuben and Reese, 1978). These densities are not significantly different.

\section{Presynaptic membrane specializations}

The presynaptic active zone represents a region along which transmitter release appears likely to take place (Heuser et al., 1979, frog; Rheuben and Reese, 1978, Manduca). The active zone from neuromuscular junctions of Manduca can be measured as the length of a narrow band or row of particles in freeze-fractured sarmples or as the length of an electron dense bar in thin-sectioned material. In the muscles of Manduca examined so far, there has been predominately only one active zone per plaque. Rarely (three out of 162) are there two (Fig. 5). The middle third axillary (slow) terminals have active zones averaging $0.211 \pm 0.06 \mu \mathrm{m}(n=57)$; subalar (fast) terminals have active zones averaging $0.236 \pm 0.054(n=31)$. Although the difference in length is not significant, other differences were observed. The active zones of slow terminals are less regular in shape (Fig. 3) than those generally seen in subalar terminals and have fewer particles on the cytoplasmic leaflet (slow terminals; 27.93 $\pm 4.51, n=18$; and 50.79 $\pm 11.87, n=14$ in fast terminals). Even though the available number of complete active zones is small, the difference is statistically significant. The active zone particles of both types of terminal seem to be of at least two distinct sizes, and pits are scen in some active zoncs. On the extcrnal leaflet, the active zone is marked by a band of both particles and pits (Figs. 5 and 6). The fractures showing the external leaflet give the impression that the slow terminals, while having fewer particles fracturing on the cytoplasmic leaflet than the fast, may have more cleaving with the external leaflet.

\section{Characteristics of the terminal as a whole}

Low-magnification views of fractures through the junctions of middle third axillary and subalar muscles reveal a difference in overall structure of the nerve terminal. The subalar (fast) junctions are characterized by a relatively even alternation between plaques on muscle processes and intervening glial processes along the sides of the terminal, and while constrictions do occasionally occur, the diameter of the terminal is largely quite even (Fig. 11). The slow junctions, on the other hand, are remarkably varicose, with most of the plaques occurring close together around enlarged regions of the terminal (Figs. 2 and 13). The extremes of largest and smallest cross-sectional diameters for slow nerve terminals were 0.2 and 2.0 $\mu \mathrm{m}$, and for fast terminals, they were 0.2 and $1.2 \mu \mathrm{m}$. (Because of the nature of the fractures, it is not possible to obtain a valid distribution of diameters.) The muscle processes that form the plaques seem to be less clearly set apart by the glial processes and are shorter in slow junctions (Fig. 13).

By combining low-magnification freeze-fracture views that show the sides and bottom of a terminal with higher-magnification views of the same terminal to identify plaques, it is possible to estimate the number of plaques/ $\mu \mathrm{m}$ of junction. (The "top" of the terminal usually does not have any plaques or regions of contact with the muscle.) In slow terminals, there are approximately $1.52 \pm 0.39$ plaques $/ \mu \mathrm{m}(n=13)$ and in fast terminals, there are $1.72 \pm 0.26$ plaques $/ \mu \mathrm{m}(n=21)$. The number of plaques per unit length has also been determined in favorable scanning electron microscope preparations of fast junctions. The light patches regularly arrayed along the length of the junction represent the highly osmiophilic postsynaptic specializations (Figs. 8 and 9; see also Fig. 1, Rheuben and Reese, 1978; and Fig. 9, Rheuben and Kammer, 1981). The number of plaques $/ \mu \mathrm{m}$ estimated by this procedure from fast terminals of the dorsal longitudinal muscle average $1.99 \pm 0.23(n=$ 16).

Scanning micrographs were used to measure the lengths of slow and fast neuromuscular junctions. Figure 12 shows a scanning micrograph of a slow junction, and Figure 8 shows several fast junctions. The slow and fast nerve terminals differ substantially in length and overall shape. Slow junctions are short $(20.15 \pm 6.04$ $\mu \mathrm{m}, \mathrm{n}=25$ ) and appear to be a single cylindrical extension of a short branch of the motor axon. The fast axon branches to form two short nerve terminals, with a pair of neuromuscular junctions being formed close together by the branches of the $y$. The mean length of one branch of a fast terminal averaged $28.52 \pm 8.9 \mu \mathrm{m}(n=24)$ from subalar muscle and $31.6 \pm 6.8 \mu \mathrm{m}(n=23)$ from the dorsal longitudinal muscle. Since the two portions of the fast junction are 


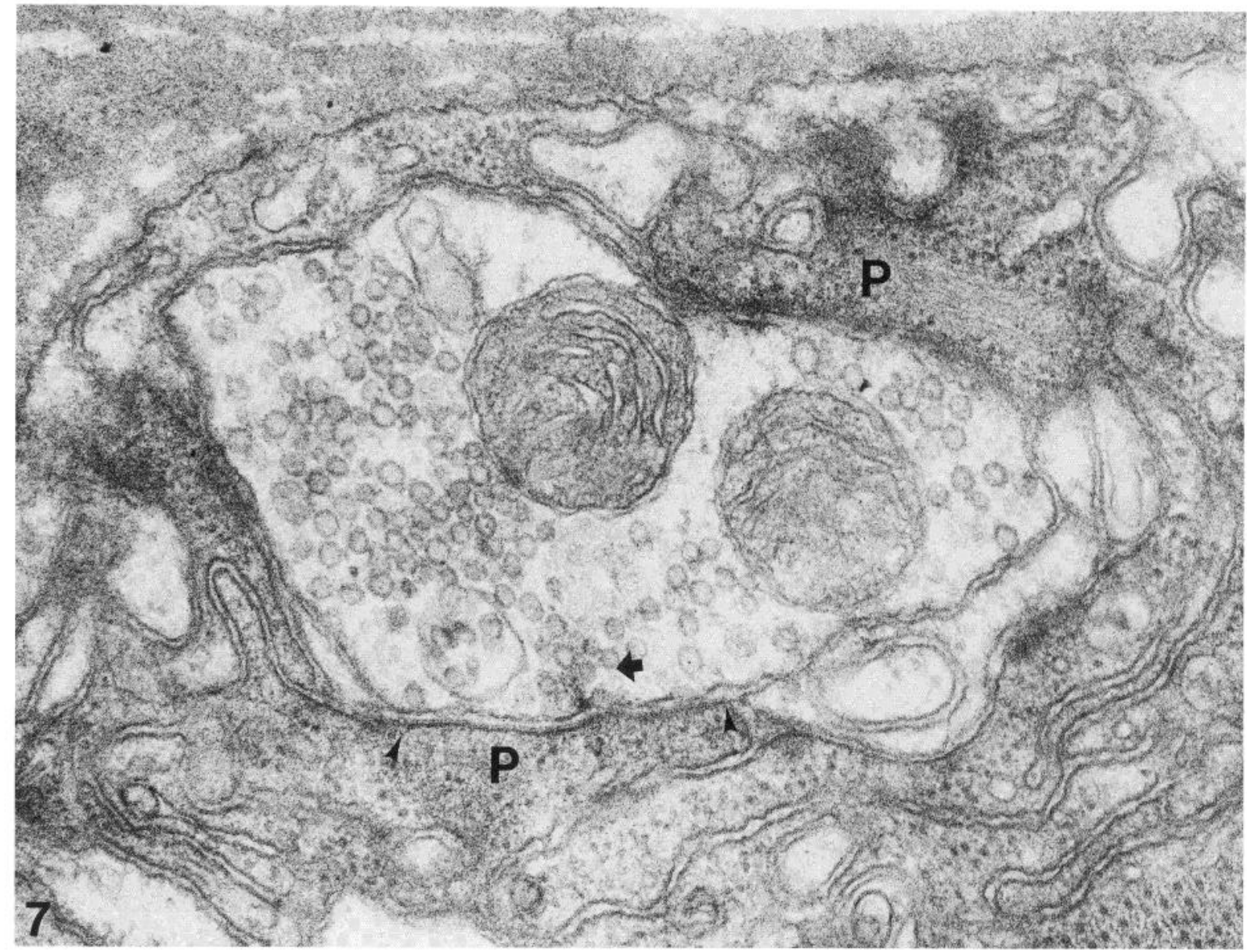

Figure 7. Cross-section of slow nerve terminal. Portions of two regions of contact with processes of the muscle fiber are shown $(P)$, one of which contains an active zone (arrow). The length of specialized, electron-dense, subsynaptic membrane is indicated by arrowheads. The terminal is well filled with synaptic vesicles. Magnification $\times 69,500$.

TABLE ॥

Comparison of muscle fiber size with area of postsynaptic plaque Muscle fiber areas were obtained from thick sections and were not corrected for tissue shrinkage.

\begin{tabular}{|c|c|c|}
\hline $\begin{array}{l}\text { Muscle (Innervation and } \\
\text { Fiber Type) }\end{array}$ & $\begin{array}{l}\text { Cross-sectional } \\
\text { Area of Fiber }\left(\mu \mathrm{m}^{2}\right)\end{array}$ & $\begin{array}{c}\text { Average Plaque Areas } \\
\left(\mu \mathrm{m}^{2}\right) \text { (measured and } \\
\text { calculated from lengths } \\
\text { and widths) }\end{array}$ \\
\hline $\begin{array}{l}\text { Middle third axillary } \\
\text { (slow n., tonic m.) }\end{array}$ & $\begin{array}{l}279 \pm 35^{8} \\
n=20\end{array}$ & $\begin{array}{c}0.334 \pm 0.114,0.317 \\
n=61\end{array}$ \\
\hline $\begin{array}{l}\text { Lower third axillary } \\
\text { (fast } \mathrm{n} \text {., intermedi- } \\
\text { ate } \mathrm{m} \text {.) }\end{array}$ & $\begin{array}{l}507 \pm 122 \\
n=20\end{array}$ & $\begin{array}{l}0.342 \pm 0.077,0.331 \\
n=13\end{array}$ \\
\hline $\begin{array}{l}\text { Upper third axillary } \\
\text { (fast } \mathrm{n} \text {., intermedi- } \\
\text { ate } \mathrm{m} \text {.) }\end{array}$ & $\begin{array}{l}903 \pm 140 \\
n=20\end{array}$ & $\begin{array}{l}0.446 \pm 0.087,0.417 \\
n=17\end{array}$ \\
\hline $\begin{array}{l}\text { Subalar (fast } \mathrm{n} . \text {, } \\
\text { phasic } \mathrm{m} . \text { ) }\end{array}$ & $\begin{array}{c}3,084 \pm 398 \\
n=20\end{array}$ & $\begin{array}{l}0.471 \pm 0.17,0.431 \\
\quad n=16\end{array}$ \\
\hline $\begin{array}{l}\text { Larval dorsal longitudi- } \\
\text { nal (fast n., tonic } \\
\text { m.) }\end{array}$ & Up to 300,000 & $\begin{array}{l}0.434 \pm 0.183,0.420 \\
\quad n=29\end{array}$ \\
\hline
\end{tabular}

\footnotetext{
${ }^{a}$ Mean \pm SD.

${ }^{D}$ Unpublished data from Schaner and Rheuben (1985).
}

so close together, they may be viewed as one structure from the point of view of the electrical properties of the postsynaptic potential recorded from muscle. The lengths of the junctions and other quantitative features are compared in Table III. The junctions in all of the muscles examined are evenly distributed along the lengths of the muscle fibers, as are the amplitudes of the recorded EJPs (Rheuben and Kammer, 1981, and present observations). This is a common situation in insect skeletal muscle which lacks a propagating action potential (Hoyle, 1983).

\section{Synaptic vesicles}

The long and short diameters of synaptic vesicles seen in thin section were measured in slow and fast nerve terminals to see if the difference reported by Titmus (1981) for locust (fast vesicles $25 \%$ larger) occurred in Manduca as well. A difference was seen, but not of the same magnitude or direction. The mean maximum diameter of vesicles in slow terminals $(45.7 \pm 6.7 \mathrm{~nm}, n=915)$ is slightly larger than that obtained from vesicles in fast terminals (43.5 \pm 4.7 $\mathrm{nm}, n=715)$. The minimum diameters are $37.0 \pm 5.8 \mathrm{~nm}(n=918)$ (slow, middle third axillary) and $35.9 \pm 4.1 \mathrm{~nm}(n=714)$ (subalar). The ratio of maximum to minimum diameters is 1.24 (slow) and 1.21 (fast). There appear to be more large vesicles and more small profiles in slow terminals. This is reflected in the appearance of the terminals (Figs. 7 and 10), the histogram of vesicle sizes (Fig. 14), and the standard deviations of the mean diameters (6.7 versus 4.7 and 5.8 versus 4.1 ). This relatively small difference in sample mean diameters (obtained from the entire populations of vesicles measured) is significant $(A<0.001)$. Values corrected for the effects of section thickness (Froesch, 1973) would be 5 to $6 \%$ larger. The data presented in the histogram are individual vesicle diameters from preparations in which both muscles were fixed at the same time (three animals). Sections from 10 or more different terminals 

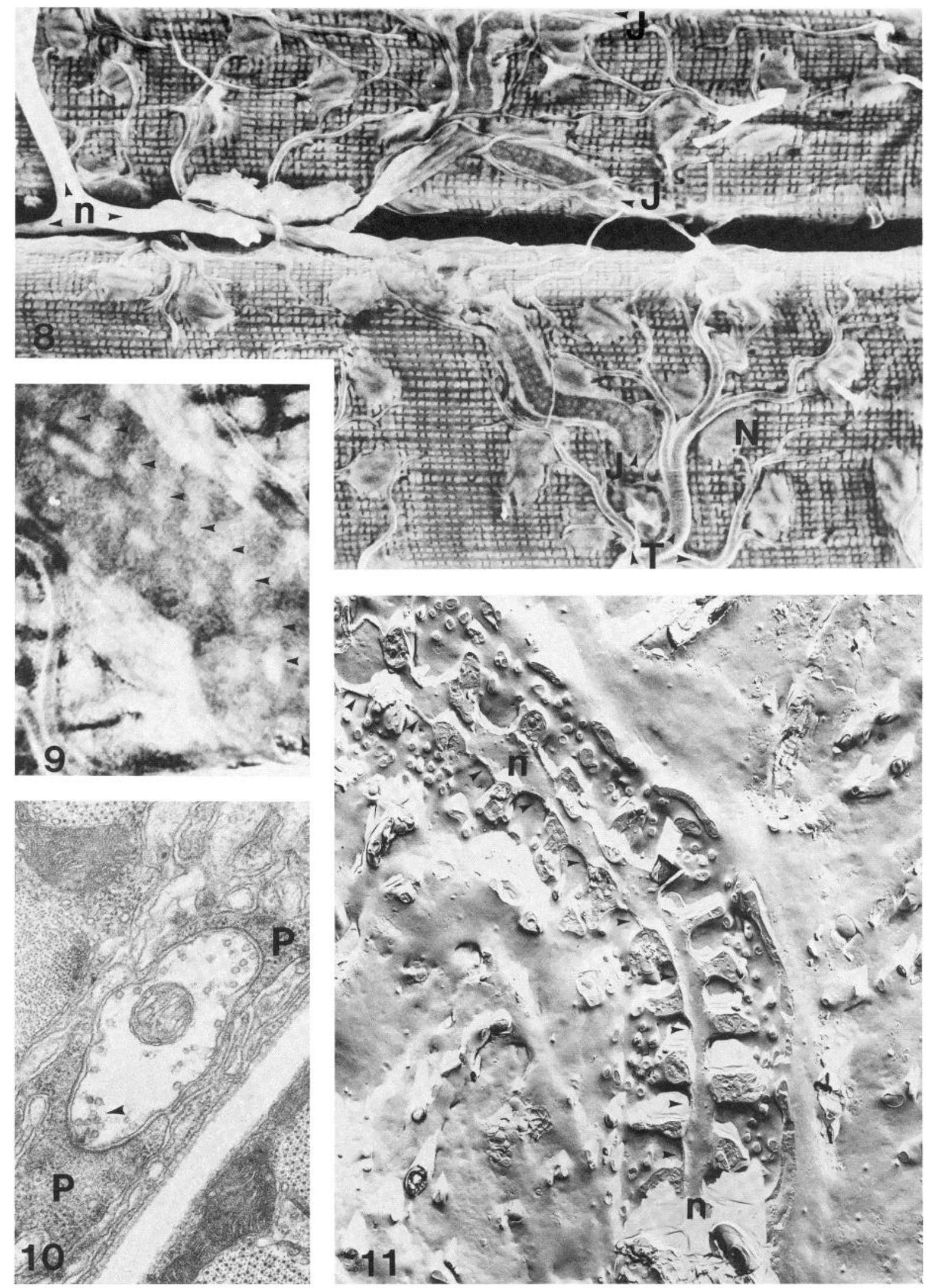

Figures 8 to 11 illustrate various aspects of fast neuromuscular junctions.

Figure 8. Scanning micrograph showing parts of two subalar muscle fibers with junctions $(J)$ from a fast motor axon. On the upper fiber, both branches of the junction are visible; on the lower, the second is on the other side of the fiber. $T$, tracheole; $N$, muscle fiber nucleus; $n$, nerve branch. The "plaid" appearance of the muscle fiber is due to the regularly arrayed mitochondria (very osmiophilic structures appear white) and the myofibrils. The tissue was not gold coated. Magnification $\times 1,400$.

Figure 9. Higher magnification scanning view of part of a fast junction. The white patches (arrows) in the junction correspond to the highly osmiophilic postsynaptic membranes. Magnification $\times 7,600$.

Figure 10. Cross-section of fast nerve terminal on subalar muscle. Two plaques are shown $(P)$, one with an active zone (arrow). Vesicle population in chemically fixed fast terminals is sparse. Magnification $\times 33,800$.

Figure 11. Low-magnification freeze-fracture view of external leaflet of subalar muscle fiber including a fast junction. The regular array of contacts (arrows) between the nerve terminal $(n)$ and the muscle fiber is interrupted by circular cross-fractured glial processes. Magnification. $\times 7,800$. 

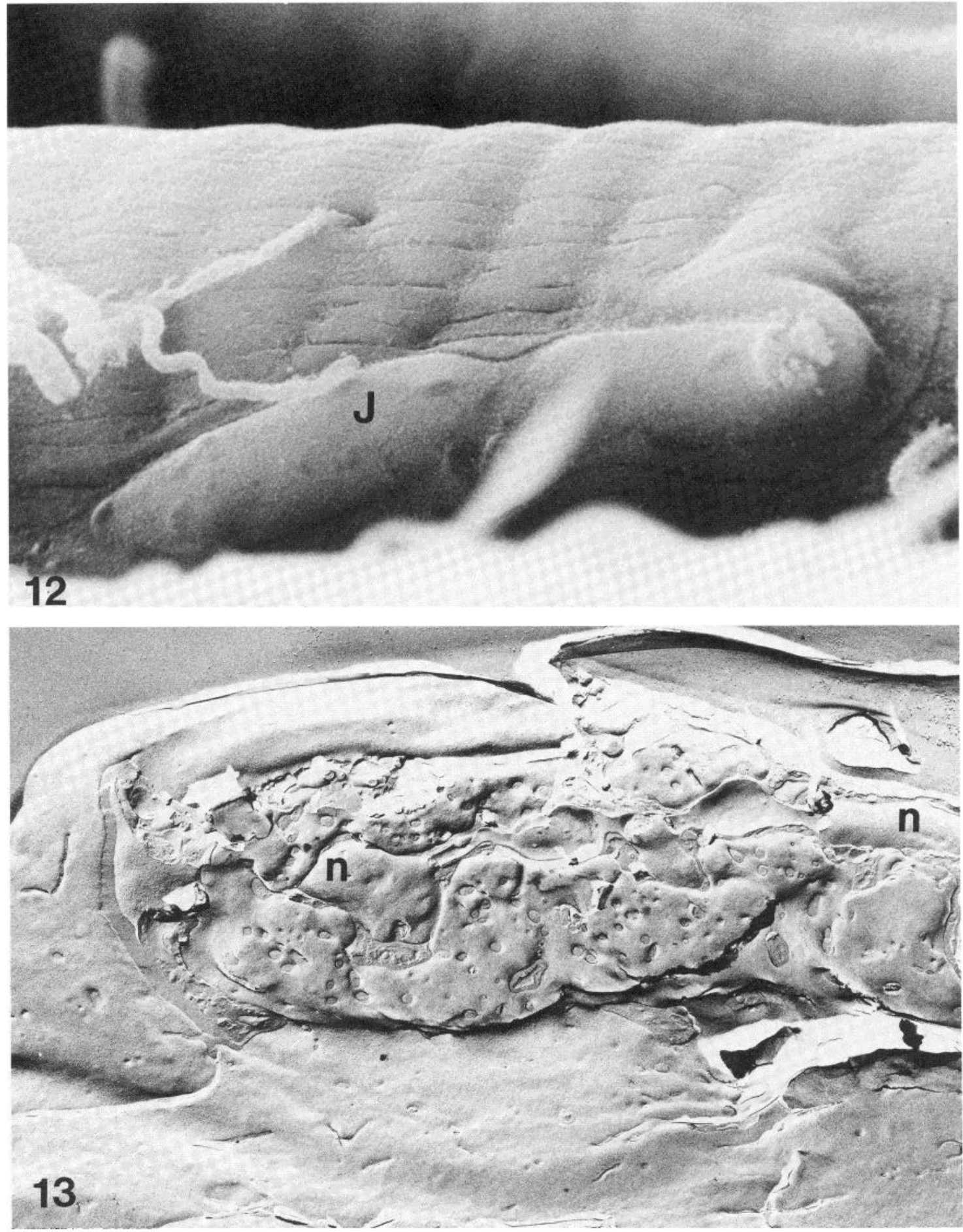

Figures 12 and 13 illustrate the external and internal structure of the slow neuromuscular junction.

Figure 12. Scanning micrograph of junction $(J)$ formed by a slow nerve terminal on a middle third axillary muscle fiber. The clefts in the muscle fiber can be seen, as well as the occasional tracheole that enters an invagination. Magnification $\times 5,500$.

Figure 13. Freeze-fracture micrograph of slow junction on middle third axillary muscle fiber. Cytoplasmic leaflet of the muscle is shown. The varicose shape of the nerve terminal $(n)$ can be compared to the shape of the fast nerve terminal in Figure 11. Magnification $\times 12,200$

were obtained from each muscle type. The difference in the populations of means of vesicle diameters obtained from individual profiles from a pair of muscles fixed from the same animal was also statistically significant using Wilcoxon nonparametric statistics. These results may be interpreted to mean that the same kind of size difference in vesicles that Titmus (1981) reported for locust, with fast being larger than slow, did not occur with the fixation applied to
Manduca. Instead, there is a real but small difference in the opposite direction. This might suggest that in both animals, the internal composition of vesicles from slow and fast terminals could be different enough to make their response to fixation different.

The slow terminal and fast terminal differ in the numbers of vesicles in the region of the plaques, with slow middle third axillary terminals having $1.68 \pm 0.46$ vesicles $/ \mu \mathrm{m}^{2}(n=35)$ and fast subalar 
TABLE III

Comparison of structural features of neuromuscular junctions of slow and fast neurons

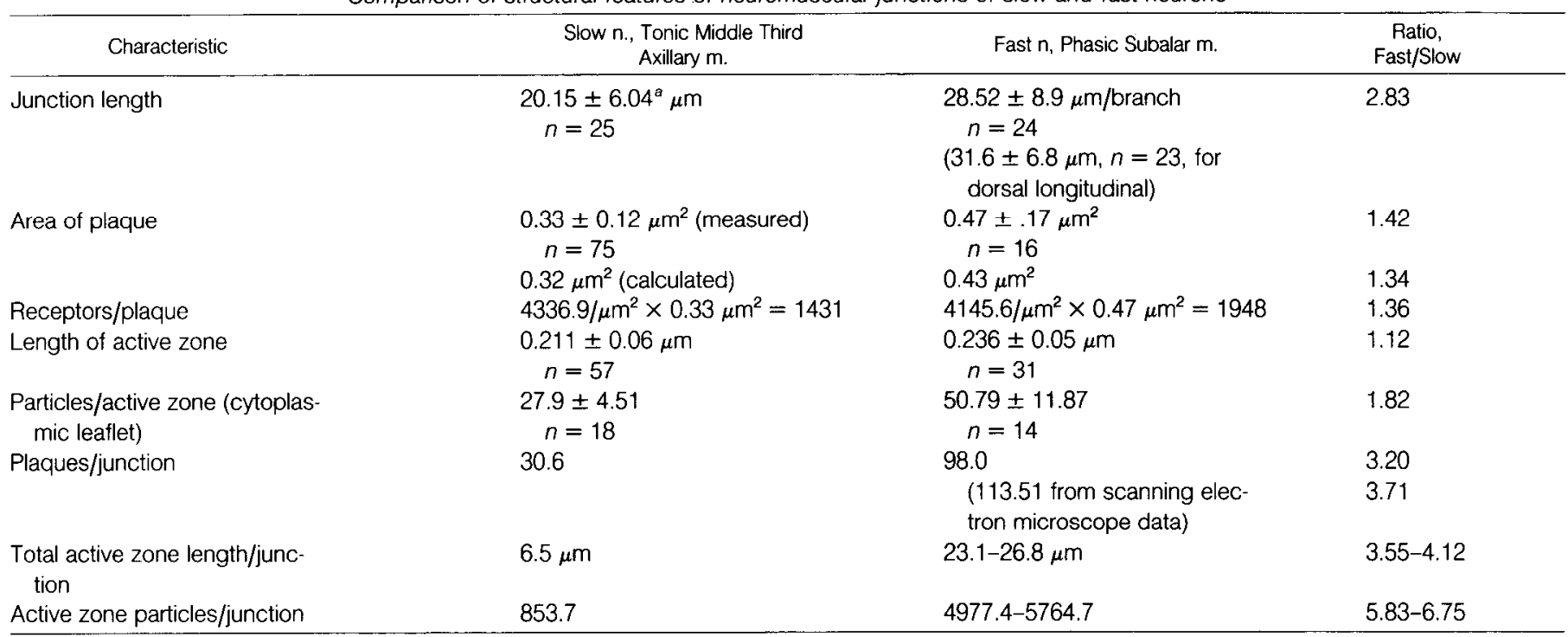

${ }^{a}$ Mean \pm SD

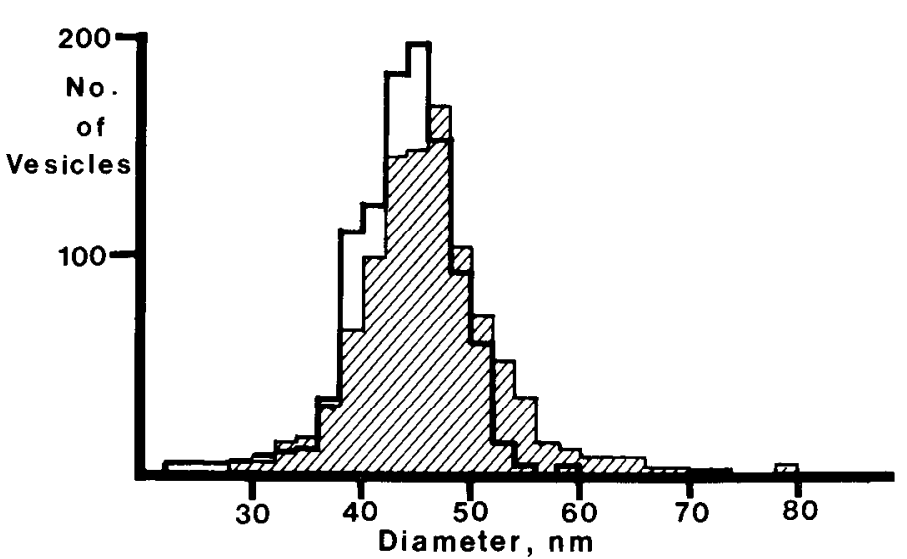

Figure 14. Histogram of maxirnum vesicle diamelers from slow (halched) and fast (open) terminals. Number of vesicles normalized to 1,000 .

terminals having $1.07 \pm 0.33$ vesicles $/ \mu \mathrm{m}^{2}(n=28)$. Counts were made of vesicles in profiles of terminals in which an active zone occurred. Area occupied by vesicles was calculated by measuring the area of the terminal and subtracting the areas of large inclusions such as mitochondria. The numbers of vesicles remaining in sectioned material is related to the conditions of fixation; for example, insect terminals fixed in high $\mathrm{Mg}^{++}$show far more densely packed vesicles (McKinlay and Usherwood, 1978). Since the muscles in this study were fixed simultaneously from the same animal, the difference observed, though not characteristic of a resting state, may still reflect intrinsic physiological properties of the two types of nerve terminals and their responses to fixative-induced depolarization.

\section{Discussion}

The object of this study was to examine structural differences between slow and fast neuromuscular junctions that might be related to their different performance. Several differences appear particularly important, including terminal length and shape, area and density occupied by postsynaptic receptors, and number and character of presynaptic active zones.

Slow junctions are shorter than fast, and they usually form only a single branch instead of being $y$-shaped. The shape of the slow nerve terminal within the junction is varicose and irregular, and the plaques are less well separated by glia. The area of each plaque, which presumably represents the area occupied by postsynaptic receptors, is smaller in slow junctions. The length of the individual active zones is about the same for slow and fast junctions, but because of the difference in the number of plaques per junction and junction length, the total length of active zone is about 3.8 times greater in fast than slow junctions. There are about twice as many particles per active zone and approximately six times as many active zone particles per junction in fast junctions. Synaptic vesicles in slow terminals are slightly larger, and the number of vesicles/profile area is greater in slow terminals than in fast under the conditions of fixation utilized in this study.

\section{Terminal length and shape}

Because the neuromuscular junctions in moths are not covered by an impermeable nerve sheath (Rheuben, 1974) and are bathed by hemolymph, which is high in $\mathrm{K}^{+}$and low in $\mathrm{Na}^{+}$(Weevers, 1966), impulse conduction in the nerve terminal membrane is probably electrotonic. Consequently, differences in the local cable properties produced by differences in the lengths and shapes of the two types of terminals might affect their space and time constants. The release of transmitter would subsequently reflect the shape of the potential change.

Although it is clear that varicosities do affect the electrotonic properties of a cable-like structure, two arguments can be raised (and are elaborated below) that it is unlikely that they alone could delay the release of transmitter enough to explain the 80-msec EJP of the slow junctions. The first is that the delay estimated on theoretical grounds is not sufficient to explain the long time course, and the second is the observation that fast terminals on several of the larval tonic muscles are also varicose (Schaner and Rheuben, 1985).

If one wishes to consider the theoretical functioning of a blindended nerve terminal the dimensions of which are not uniform, and the input of which is a brief pulse, both the space constant and the time course of decay of a pulse are relevant in their effects on the release of transmitter along its length. The space constant of a cylindrical structure is proportional to the diameter, and in cases in which the potential change is brief, it is less than the steady-state space constant (Katz and Miledi, 1968). The model derived by Ellias and Stevens (1980) predicts that the space constant of a constricted structure is shorter than one for a structure of constant diameter. Using estimates of internal resistance, membrane resistance, and membrane time constant from other preparations (Hodgkin and 
Rushton, 1946; Zucker, 1972; Atwood, 1976) and the measurements of diameter from the slow and fast terminals studied here, one can estimate the space constants. Choosing values to obtain minimum estimates (because of the work of Ellias and Stevens, 1980), one obtains $30 \mu \mathrm{m}$ for the varicose slow terminal and $47 \mu \mathrm{m}$ for the fast terminal. The ratio of average length of cable (measured from the nerve leminals) to the space constant estimaled from the measured diameters is quite similar for the two terminals: 0.66 and 0.64 (or 0.28 and 0.27 for the steady-state space constants) for slow and fast terminals, respectively.

The effect of the blind end on electrotonic decay of potential is to decrease the decline in polential loward the end of the terminal and to increase the time that the potential takes to decay. The models of Jack and Redman (1971) for short cables with sealed ends predict that the time course of decay is progressively prolonged as one moves away from the site of origin of the current pulse. The prolonged time course of an action potential at the end of a terminal was observed experimentally by Katz and Miledi (1964). The models of Jack and Redman (1971: Fig. 8) also predict that the time course of decay is prolonged as the actual cable length is shortened relative to the length constant. Since the ratio of the length of cable to the space constant is not remarkably different for the two terminals, the effect of the constrictions may have been compensated for by a shortening of the terminal, making the varicose shape unlikely to be the source of the difference in time course of the two EJPs. Furthermore, using a "worst case" large value for the time constant of the terminal membrane of $\tau_{m}=5 \mathrm{msec}$ and the curves published by Jack and Redman (1971), one can estimate that the decay of potential to near zero at the tip of either of these junctions would not be expected to last for more than $30 \mathrm{msec}$. Of these $30 \mathrm{msec}$, only a part would include potential change appropriate to induce $\mathrm{Ca}^{++}$influx and subsequent transmitter release. This is substantially less than the $80-\mathrm{msec}$ duration of the slow EJPs, indicating that at least part of the mechanism underlying the long time course is likely to lie elsewhere.

An empirical observation also argues against the constrictions being the source of the long time course of the slow EJPs. The varicose shape has also been observed in the fast terminals of larval motor neurones in Manduca (Schaner and Rheuben, 1985). In this case, the fast motor neurones are innervating tonic muscle fibers; later, those same neurones will innervate a phasic flight muscle, the dorsal longitudinal muscle (Rheuben and Kammer, 1980), forming the fast nonvaricose terminals described in this study and previously (Rheuben and Reese, 1978).

Although it does not appear likely that the varicose shape can explain the time course, two other correlations might be considered for future study. In both the larval muscle and the middle third axillary, the muscle fibers are tonic, even though one is innervated by a slow axon and one by a fast. Consequently, it is possible that this element of the jointly constructed neuromuscular junction may be determined developmentally by the postsynaptic cell. Atwood et al. (1984) have pointed out that the efficacy of presynaptic inhibition is likely to be enhanced in varicose structures. While there is no evidence of inhibitory innervation of the muscles uscd in this study, there may be evolutionary reasons for this shape of terminal to be formed in conjunction with certain muscle fiber types. In insects, multiple innervation, including an inhibitory axon, is not usually found on the phasic flight muscles but is more likely to be found on tonic or intermediate muscles used for walking or postural control.

The greater length of releasing nerve terminal at each fast neuromuscular junction has the effect of locally producing an EJP which is above threshold for the active membrane response in the nearby muscle membrane. Although this "spike" does not propagate, its greater depolarization and more rapid repolarization would have functional benefits in terms of contraction amplitude and time course. As with the slow junctions, an even distribution of terminals is required for uniform contraction.

\section{Factors affecting time course of conductance change}

Subsequent to the release of transmitter into the synaptic cleft, there are a number of factors which are known to affect the time course of the conductance change and of the endplate potential in the postsynaptic membrane: the physical dimensions and boundaries of the cleft, the area and density of postsynaptic receptors, the presence or absence of an inactivating substance, and the properties of the receptor ion channel complexes.

In the vertebrate cholinergic junction, studies of miniature endplate currents (MEPCs) have implicated one or more of these factors in the production of different types of EJP. Harvey and van Helden (1981), in a study of the anterior (slow) and posterior (fast) latissimus dorsi muscles of the chicken, which are singly and multiply innervated, respectively, found that ALD junctions produced a greater frequency of MEPCs with slow growth times and slow decay times. Analysis of ACh-induced noise, however, did not indicate any difference in average lifetime of $\mathrm{ACh}$ channels in the two types of junctions.

In the neuromuscular junctions of twitch and slow fibers in the snake, the decay rate of the miniature endplate currents of slow fiber endplates was much less sensitive to voltage changes across the postsynaptic membrane than in fast muscle fibers. The decay rates of MEPCs themselves differed, and the time to peak current was longer in slow fibers. Differences in ACh-induced spectra indicated that properties of the channels in the two types of junctions are different, and estimates of mean single channel conductance are $20 \%$ smaller for slow fibers in this preparation (Dionne and Parsons, 1981). Similarly, Federov et al. (1982) found that, in the slow muscle fibers of frogs, in which the MEPCs have slower rise times and decay times than those in fast fibers, the channel life times were longer and single channel conductances were less. In addition, the decay of MEPCs in slow fibers is slower than the time constant of the noise, and there is a greater dispersion of the time course of the MEPCs from slow junctions.

Taken together, these results suggest that channel properties may frequently be a source of differences between junctions using the same transmitter substance. However, at the same time, the existence of other differences in the junctions is also strongly implicated. In the insects, there are substantially fewer data to distinguish these factors.

In the locust, the duration of "normal" miniature endplate currents is about $10 \mathrm{msec}(\tau=2.5 \mathrm{msec})$. Occasionally, very long MEPCs are interspersed among the others (Cuil-Candy and Miledi, 1982). Even though these data may have been obtained from fibers with both fast and slow innervation (distal portion of the extensor tibia), there is no clear indication of two populations of decay times.

The morphological results presented here neither suggest nor deny possible differences in the channel properties of the two types of junction. The particles in the postsynaptic plaques are not markedly different in shape or arrangement in the membrane as they are, for example, between excitatory and inhibitory junctions in crayfish (Franzini-Armstrong, 1976). Consequently, any differences in channel properties that would give rise to the difference in time course of the two types of EJP will have to be resolved at the physiological level; the previously discussed work on vertebrate junctions would point to the importance of doing so.

In a model system devised for the cholinergic junction, Wathey et al. (1979) predict that an increase in density of receptors would increase the number of channels open at peak and slow the rate of decay of the quantal event. There is only a slight increase in density of postsynaptic particles in slow junctions over fast. While the difference in density observed is in the direction to support the hypothesis of a role in producing a longer EJP, it is not statistically significant.

In addition to the density and properties of the receptor-ion channel complexes, the size and shape of the patch that they occupy will influence the amplitude and time course of the quantal 
event. The actual voltage change that is produced will depend both on the magnitude of the quantal current and on the size (input resistance) of the postsynaptic cell. The size of the patch is likely to be tailored to the amount of transmitter in an ordinary event: in relatively small patches, fewer receptor-ion channels will be available for binding, and the peak current would be limited by saturation; in large patches, the endplate current will take longer to decay because of repetitive binding. Wathey et al. (1979) calculate, for a system without an inactivating enzyme and with 10,000 molecules of transmitter per vesicle, that peak activation does not continue to increase for patches bigger than $0.5 \mu \mathrm{m}$ in radius, but that half-decay times increase with the radius up to $1.0 \mu \mathrm{m}$. In Manduca, the slow plaques average $0.32 \mu \mathrm{m}$ in radius and the fast plaques average $0.37 \mu \mathrm{m}$, providing significantly different areas occupied by receptors. However, the difference in time course of the two types of EJP cannot be predicted from this consideration - it is in the opposite direction if their respective quantal events were to be prolonged by repetitive binding.

My data suggest a weak correlation of average area of postsynaptic receptor patches (plaque area) with muscle fiber size for the smaller muscle fibers. This makes sense from the point of view of input resistance. Furthermore, larger excitatory postsynaptic patches were reported on larger crustacean muscle fibers (Hill and Govind, 1981). However, in the locust nerve muscle combinations studied by Titmus (1981), the reverse relationship was observed. Even though the combinations that she studied were similar to the ones reported here (fast motor neuron innervating large phasic muscle fibers and slow motor neurones innervating small-diameter tonic muscle fibers (Hoyle, 1978)), the reverse relationship of plaque area to either "slowness" or fiber diameter prevailed. Although more data would be a welcome addition to the study of this question, it is also possible to consider that other factors combine to determine what the optimal area of a cluster of receptors should be for a particular function. One factor that is likely to be important in comparing junctions of different types is whether or not an active zone, as seen structurally, and its corresponding patch of receptors represent a single functional unit

At the crayfish neuromuscular junction, the number of transmitter release sites correlates with the number of morphologically recognizable active zones (Zucker, 1973). These studies showed that in normal saline, a single stimulus released a single quantum from only a fraction of the two to four release sites within range of the extracellular electrode. This relatively low normal usage of active zones during single impulses was also reported for the frog neuromuscular junction, where one quanturn was released for every two or three active zones, each about $1 \mu \mathrm{m}$ in length, in $10 \mathrm{~mm}$ calcium, but where release could be increased to 12.9 vesicles per micrometer of active zone in 4-amino pyridine (Heuser et al., 1979). Korn et al. (1982) found a good correlation between $n$ and the number of boutons on Maultiner cells, with $\rho$, the probability of release, also being low, about 0.37 . This would suggest that, for at least some synapses, the normal operating condition is the release of one or no quanta per unit structure for each action potential. The unitary structure might be viewed as an active zone or segment of an active cone and a certain adjacent area of receptor membrane. Very large areas of receptors might then be associated with multiple active zones or other modifications in function. This possibility is supported by the data tabulated by Govind and Chiang (1979), which showed for both low output and high output junctions formed by a single motor neuron of lobster that double or triple active zones occur opposite the larger contact regions. Similar observations were made by Jahromi and Atwood (1974) and Atwood (1976) for the axons innervating the opener muscle of the crayfish, and a recent extensive analysis (Atwood and Marin, 1983) on low output and high output terminals of a single motor neuron in the crab Hyas reports both different lengths of active zones and multiple active zones in the larger contact regions. Their minimum active zone length is described as about $0.15 \mu \mathrm{m}$. If that length is taken as some sort of functional unit and divided into the active zone perimeters that they tabulate and therr is compared with the area of postsynaptic contact, a relatively constant relationship is obtained. Each "unitary active zone" of $0.15 \mu \mathrm{m}$ is accompanied by $0.54 \mu \mathrm{m}^{2}$ (low output), 0.56 $\mu \mathrm{m}^{2}$ (intermediate output) or $0.6 \mu \mathrm{m}^{2}$ (high output) of synapse contact area.

Titmus's (1981) seemingly contradictory observations correlating larger postsynaptic patch size with slow junctions can then be explained by considering the numbers of active zones. Unlike the junctions in the moth, the very large postsynaptic areas (diameter $1.7 \mu \mathrm{m}$, slow; $1.2 \mu \mathrm{m}$, fast) that she observed in locust were associated with multiple active zones, and more double and triple active zones were associated with the larger contact regions of the slow terminals (personal communication). Consequently, the direct comparison of the synapse areas of locust slow and fast junctions with those of the moth which have essentially only one active zone per plaque is not useful to decide if smaller plaque area is either a characteristic related to "slowness" or if other factors such as muscle fiber diameter are more important. It may be that the same relationship as in Manduca would be found if the number and length of the active zones could be taken into account.

It is clear that more measurements of active zones and postsyn aptic patches with known physiological properties are needed to clarify this issue. The presently available data are not inconsistent with the possibility that postsynaptic cell size or input resistance is important in influencing the size of a "unitary" postsynaptic patch of receptors. On the other hand, there is no particular support, either theoretical or empirical, for the hypothesis that differences in postsynaptic patch areas seen in these various arthropod neuromuscular junctions are the sources of their differences in EJP duration. Furthermore, the interaction of a very large or growing postsynaptic cell with its innervating nerve is likely to include such complications as the formation of more junctions or longer junctions, as seen in a comparison of first instar larval and adult locust muscle fibers (Walther, 1981), as well as larger postsynaptic patches.

\section{Properties of the presynaptic active zone}

In insect muscle, the multiterminal nerve endings are evenly distributed, and the amplitude of the intracellularly recorded EJP is constant over the length of the fiber. The fast EJPs studied here are at least three to five times greater in peak amplitude than are slow EJPs. Since the length of each individual active zone is essentially the same in both nerve types, the relative difference in numbers of active zones per junction could help to explain the difference in peak amplitude of the EJPs. However, the estimate of 3.2 to 3.7 times more active zones in fast junctions is at the low end of the expected range.

In a number of previous studies on crustaceans, a good qualitative correlation has been established between transmitter output and total number or length of active zones; however, a linear quantitative relationship has not been demonstrated (Atwood and Marin, 1983). Active zones of the same length may have different properties in different types of junction. Such a difference might only be reflected in another parameter such as number of particles, as was observed between the slow and fast junctions in Manduca

It has been suggested that the particles seen in freeze-fracture at the active zone represent $\mathrm{Ca}^{++}$channels (Heuser et al., 1974), and there appears to be order-of-magnitude agreement between the number of large intramembrane particles at the active zones in the squid giant synapse and the total number of calcium channels expected from voltage clamp measurements and from single channel conductances (Pumplin et al., 1981).

If (1) an active zone (or perhaps a segment of a long active zone) is designed to release a single quantum of transmitter independent of release at other active zones, (2) probability of release is dependent in part on intracellular $\mathrm{Ca}^{++}$immediately adjacent to the release site, and (3) facilitation involves a residual accumulation of $\mathrm{Ca}^{++}$in that vicinity (Charlton et al., 1982; Zucker, 1982), then it might be 
reasonable to expect active zones with fewer $\mathrm{Ca}^{++}$channels to have a lower probability of release to the first stimulus and different facilitation properties. If the probability of release is a compound function, with one factor being the $\mathrm{Ca}^{++}$concentration near the active zone and another being a factor involving the number of vesicles ready to be released, low transmitter release and greater facilitation in slow terminals could be explained as follows:

(1) The number of $\mathrm{Ca}^{++}$channels (particles) is relatively low, so that a single action potential would produce a $\mathrm{Ca}^{++}$concentration only adequate to provide a relatively low probability of release of a quantum. (2) The mobilization system or organization system of prirned vesicles is such that release of a second carl occur readily. (This possibility is supported by the greater numbers of vesicles remaining near the active zone in chemically fixed terminals.) (3) $\mathrm{Ca}^{++}$accumulates in the region of the active zone such that a second action potential increments the $\mathrm{Ca}^{++}$level and increases the proportion of active zones releasing quanta.

In contrast, fast terminals with more $\mathrm{Ca}^{++}$channels and a poorer mobilization system would release most of the ready, available quanta and would produce no more or perhaps fewer quanta to the second stimulus. It is true that in this preparation the first fast EJP after a rest is larger than those in a train, even at intervals of one stimulus every 2 seconds. Further evaluation of this idea will require quantal analysis and structural examination of specific terminal types.

A small difference in the size and shape of the synaptic vesicles occurs between slow and fast terminals, as has been previously reported for vesicles from locust (Titmus, 1981). The physiological significance of the difference we see would have to be conjectural at this point. Such ingenious mechanisms as packaging the transmitter with an auxiliary substance that affects diffusion properties or re-uptake might be a way of lengthening the time course of the quantal event and could be reflected by the postfixation vesicle size.

Finally, a difference in the relative proportion of glial processes and muscle processes around the nerve terminal was noted but not quantified for the two types of neuromuscular junctions. Since glutamate, the putative transmitter substance in insects, is not known to be inactivated by an enzyme in the cleft as is ACh, but rather is thought to be taken up by both the nerve terminal and the adjacent glial cells (Faeder and Salpeter, 1970; Briley et al., 1982), a difference in relative availability of re-uptake sites might lead to some differences in time course if large amounts of transmitter are released.

In summary, the structure-function correlations that have been suggested include: (1) the length of the individual branches of a junction may be limited (by electrotonic factors?), with the length of varicose terminals being more restricted; (2) plaque size per unit active zone may be related in part to the postsynaptic fiber diameter; and (3) EJP amplitude and facilitation may be related to the number of active zones per junction, to the number of $\mathrm{Ca}^{++}$channels/ particles in an active zone, and to the number and organization of readily released vesicles.

None of the morphological differences that were observed could directly be cited as a cause for the long time course of the slow EJP. The possibility of the time course being related to differences in the individual charactcristics or distribution of receptor-ion channel complexes is not supported by the morphological data but cannot be excluded by it at present. Electrophysiological data from other insects also does not provide clear-cut evidence that the characteristics of the unitary event are different enough to explain the time course of the two types of EJP. It is clear that this possibility, as well as any differences provided by composition of vesicular content and re-uptake mechanisms, require more detailed quantal analysis of known nerve terminal types in order to assess their likelihood as mechanisms. Should these prove to be unlikely, one additional mechanism remains to be suggested for testing. It is possible that irregular conduction velocities in the fine nerve branches to the distributed endings causes asynchronous release from the junctions, giving a longer time course of the intracellularly recorded postsyn- aptic response. There are at present no morphological or physiolog ical data available to assess this possibility.

\section{References}

Aizu, S. (1982) Morphological differences between excitatory and inhibitory nerve terminals in cockroach coxal muscles. Tissue Cell 14: 329-339.

Atwood, H. L. (1976) Organicalion and synaptic physiology of crustacean neuromuscular systems. Progr. Neurobiol. 7: 291-391.

Atwood, H. L., F. Lang, and W. A. Morin (1972) Synaptic vesicles: Selective depletion in craytish excitatory and inhibitory axons. Science 176: 13531355.

Atwood, H. L., and L. Marin (1983) Ultrastructure of synapses with different transmitter-releasing characteristics on motor axon terminals of a crab, Hyas areneas. Cell Tissue Res. 231: 103-115.

Atwood, H. L., J. K. Stevens, and L. Marin (1984) Axo-axonal synapse location and consequences for presynaptic inhibition in crustacean motor axon terminals. J. Comp. Neurol. 225: 64-74.

Briley, P. A., M. Filbin, G. Lunt, and J. Donnellan (1982) Binding and uptake of glutamate and $\boldsymbol{\gamma}$-aminobutyric acid in membrane fractions from locust muscle. In Neuropharmacology of Insects, Ciba Foundation Symposium 88, pp. 176-198, Pitman, London.

Charlton, M. P., S. J. Smith, and R. S. Zucker (1982) Role of presynaptic calcium ions and channels in synaptic facilitation and depression at the squid giant synapse. J. Physiol. 323: 1/3-193.

Cull-Candy, S. G., and R. Miledi (1982) Properties of miniature excitatory junctional currents at the locust nerve-muscle junction. J. Physiol. 326 . $527-551$.

Dionne, V. E., and R. L. Parsons (1981) Characteristics of the acetylcholineoperated channel at twitch and slow fibre neuromuscular junctions of the garter snake. J. Physiol. 310: 145-158.

Dreyer, F., K. Peper, K. Akert, C. Sandri, and H. Moor (1973) Ultrastructure of the "active zone" in the frog neuromuscular junction. Brain Res. 62 . 373-380.

Ellias, S. A., and J. K. Stevens (1980) The dendritic varicosity: A mechanism for electrically isolating the dendrites of cat retinal amacrine cells? Brain Res. 196: 365-372.

Evan, A. P., W. G. Dail, D. Dammrose, and C. Palmer (1976) Scanning electron microscopy of cell surfaces following removal of extracellular material. Anat. Rec. 186: 433-446.

Evans, P. D., and M. O'Shea (1978) The identification of an octopaminergic neurone and the modulation of a myogenic rhythm in the locust. J. Exp. Biol. 73: 235-260.

Evans, P. D., and M. V. S. Siegler (1982) Octopamine mediated relaxation of maintained and catch tension in locust skeletal muscle. J. Physiol. 324 93-112.

Faeder, I., and M. Salpeter (1970) Glutamate uptake by a stimulated insect nerve muscle preparation. J. Cell Biol. 46: 300-307.

Fambrough, D. M. (1979) Control of acetylcholine receptors in skeletal muscle. Physiol. Rev. 59: 165-227.

Fedorov, V. V., L. G. Magazanik, V. A. Snetkov, and A. L. Zefirov (1982) Postsynaptic currents in different types of frog muscle fibre. Pflügers Arch. 394: 202-210.

Franzini-Armstrong, C. (1976) Freeze-fracture of excitatory and inhibitory synapses in crayfish neuromuscular junctions. J. Microscopie Biol. Cell. 25: 217-222.

Froesch, D. (1973) A simple method to estimate the true diameter of synaptic vesicles. J. Microsc. 98: 85-89.

Govind, C. K., and R. G. Chiang (1979) Correlation between presynaptic dense bodies and transmitter output at lobster neuromuscular terminals by serial section electron microscopy. Brain Res. 161: 377-388.

Harvey, A. L., and D. van Heiden (1981) Acetylcholine receptors in singly and multiply innervated skeletal muscle fibers of the chicken during development. J. Physiol. 317: 397411.

Heuser, J. E., T. S. Reese, and D. M. D. Landis (1974) Functional changes in frog neuromuscular junctions studied with freeze-fracture. J. Neurocytol. 3: 109-131.

Heuser, J. E., T. S. Reese, M. J. Dennis, Y. Jan, L. Jan, and L. Evans (1979) Synaptic vesicle exocytosis captured by quick freezing and correlated with quantal transmitter release. J. Cell Biol. 81: 275-300.

Hill, R. H., and C. K. Govind. (1981) Comparison of fast and slow synaptic terminals in lobster muscle. Cell Tissue Res. 221: 303-310.

Hodgkin, A. L., and W. A. H. Rushton (1946) The electrical constants of a crustacean nerve fibre. Proc. R. Soc. (Biol.) 133: 444-479.

Hoyle, G. (1975) The neural control of skeletal muscles. In Insect Muscle, P. N. R. Usherwood, ed., Academic Press, Inc., New York. 
Hoyle, G. (1978) Distributions of nerve and muscle fibre types in locust jumping muscle. J. Exp. Biol. 73: 205 233.

Hoyle, G. (1983) Muscles and Their Neural Control, pp. 487-491. John Wiley \& Sons, New York.

Hoyle, G., W. Colquhoun, and M. Williams (1980) Fine structure of an octopaminergic neuron and its terminals. J. Neurobiol. 11: 103-126.

Jack, J. J. B., and S. J. Redman (1971) The propagation of transient potentials in some linear cable structures. J. Physiol. 215: 283-320.

Jahromi, S. S., and H. L. Atwood (1974) Three-dimensional ultrastructure of the crayfish neuromuscular apparatus. J. Cell Biol. 63: 599-613.

Katz, B., and R. Miledi (1964). Propagation of electric activity in motor nerve terminals. Proc. R. Soc. (Biol.) 161: 453-482.

Katz, B., and R. Miledi (1968) The effect of local blockage of motor nerve terminals. J. Physiol. 199: 729-741.

Korn, H., A. Mallet, A. Triller, and D. S. Faber (1982) Transmission at a central inhibitory synapse. II. Quantal description of release, with a physical correlate for binomial n. J. Neurophysiol. 48: 679-707.

McKinlay, R. G., and P. N. R. Usherwood (1978) The effects of magnesium ions on the fine structure of the insect neuromuscular junction. J. Ultrastr. Res. 62: 83-93.

Meiss, D. E., and C. K. Govind (1980) Heterogeneity of excitatory synapses at the ends of single muscle fibers in lobster Homarus americanus. J. Neurobiol. 11: 381-395

Nakajima, Y., and T. S. Reese (1983) Inhibitory and excitatory synapses in crayfish stretch receptor organs studied with direct rapid-freezing and freeze-substitution. J. Comp. Neurol. 213: 66-73.

Pichon, Y. (1974) Axonal conduction in inscets. In Fronticrs of Biology, Vol. 35, Insect Neurobiology, J. E. Treherne, ed., pp. 73-117, Elsevier/NorthHolland Biomedical Press, Amsterdam.

Pumplin, D. W., T. S. Reese, and R. Llinas (1981) Are the presynaptic membrane particles the calcium channels? Proc. Natl. Acad. Sci. U. S. A. 78: 7210-7213.

Rash, J. E., and M. H. Ellisman (1974) Studies of excitable membranes. I. Macromolecular specializations of the neuromuscular junction and the non-junctional sarcolemma. J. Cell Biol. 63: 567-586.

Rheuben, M. B. (1972) The resting potential of moth muscle fiber. J. Physiol. 225: 529-554.

Rheuben, M. B. (1974) The permeability of the synaptic complex of the moth neuromuscular junction. Physiologist 17: 338 .
Rheuben, M. B., and A. E. Kammer (1980) Comparison of slow larval and fast adult muscle innervated by the same motor nouronc. J. Exp. Biol. 84: 103-118.

Rheuben, M. B., and A. E. Kammer (1981) Membrane structure and physiology of an immature synapse. J. Neurocytol. 10: 557-575

Rheuben, M. B., and A. E. Kammer (1983) Mechanisms influencing the amplitude and time course of the excitatory junction potential. In The Physiology of Excitable Cells, A. D. Grinnell and W. Moody, eds., pp. 393-409, Alan R. Liss, Inc., New York.

Rheuben, M. B., and T. S. Reese (1978) Three-dimensional structure and membrane specializations of moth excitatory neuromuscular synapse. $\mathrm{J}$. Ultrastruct. Res. 65: 95-111.

Rosenbluth, F. (1978) Particle arrays in earthworm post-junctional membranes. J. Cell Biol. 76: 76-86.

Schaner, P. J., and M. B. Rheuben (1985) Scanning and freeze-fracture study of larval nerves and neuromuscular junctions in Manduca sexta. J. Neurobiol. 16: 83-96.

Titmus, M. J. (1981) Ultrastructure of identified fast excitatory, slow excitatory, and inhibitory neuromuscular junctions in the locust. J. Neurocytol. 10: 363-385.

Uchizono, K. (1967) Inhibitory synapses on the stretch receptor neurone of the crayfish. Nature 214: 833-834.

Walther, C. (1981) Synaptic terminals from an identified motoneuron in locust: Comparison between first instar larva and adult. Neurosci. Lett. 27: 237242.

Wathey, J. C., M. M. Nass, and H. A. Lester (1979) Numerical reconstruction of the quantal event at nicotinic synapses. Biophys. J. 27: 145-164.

Weevers, R. (1966) A lepidopteran saline: Effects of inorganic cation concentrations on sensory, reflex and motor responses in a herbivorous insect. J. Exp. Biol. 44: 163-175.

Yamamoto, R. T. (1969) Máss rearing of the tobacco hornworm. II. Larval rearing and pupation. J. Econ. Ent. 62: 1427-1431.

Zucker, R. S. (1972) Crayfish escape behavior and central synapses. III. Electrical junctions and dendrite spikes in fast flexor motoneurons. $\mathrm{J}$. Neurophysiol. 35: 638-651.

Zucker, R. S. (1973) Changes in the statistics of transmitter release during facilitation. J. Physiol. 229: 787-810.

Zucker, R. S. (1982) Processes underlying one form of synaptic plasticity: Facilitation. In Conditioning. Representation of Involved Neural Functions, C. D. Woody, ed., pp. 249-264, Plenum Press, New York. 